\title{
Contents of Ecotoxic Elements in Polish Coking Bituminous Coals and in Products of Coking
}

\author{
Piotr Burmistrz ${ }^{1}$, Tadeusz Dziok ${ }^{1, *}$, Dorota Makowska ${ }^{1}$, Faustyna Wierońska ${ }^{1,2}$, \\ and Andrzej Strugała ${ }^{1}$ \\ ${ }^{1}$ AGH University of Science and Technology, Faculty of Energy and Fuels, Al. A. Mickiewicza 30, \\ 30- 059 Krakow \\ ${ }^{2}$ AGH University of Science and Technology, AGH Centre of Energy, ul. Czarnowiejska 36, \\ 30-054 Krakow
}

\begin{abstract}
Ecotoxic elements include the ones which have a negative impact on human health and the environment, among others, mercury, arsenic and lead. Hard coal is a fuel which contains significant amounts of ecotoxic elements and the processes of coal combustion, coking and gasification are one of the main sources of their anthropogenic emission. In the coking process, individual ecotoxic elements in various proportions remain in coke and are released to the raw coke oven gas. During the cleaning and cooling of coke gas, ecotoxic elements are distributed between purified coke gas and other coking byproducts. In the paper, the measurement results of the contents of selected ecotoxic elements in the Polish coking bituminous coals are presented, i.e. mercury, arsenic and lead. The examination results of their content in the products of the coking process i.e. coke, coal tar, BTX, sulfur, and purified coke oven gas are also shown. Coke is characterized by a much lower content of mercury and lead than coal, and by a similar content of arsenic. Among the coking products, sulfur and tar are characterized by the highest content of mercury. Coal tar also contains a high amount of lead.
\end{abstract}

\section{Introduction}

Ecotoxic elements include the ones which have a negative impact on human health and the environment [1]. The highest toxicity is displayed, among others, by mercury, arsenic, lead, cadmium, nickel, thallium as well as chromium [2]. They may cause numerous dysfunctions of the human body and most of them are carcinogenic.

Hard coal is a fuel which contains significant amounts of ecotoxic elements [3-5] and the processes of coal combustion, coking and gasification are one of the main sources of their anthropogenic emission [6-8]. In the combustion and gasification processes, individual ecotoxic elements are released from coal and in various proportions pass into both solid byproducts (ash or slag) and flue gases or syngas. According to data presented in work [9], due to the different volatility of the ecotoxic elements, they could by divided into three groups:

\footnotetext{
* Corresponding author: tadeusz.dziok@agh.edu.pl
} 
- group 1 - the elements of low volatility, which pass into the bottom ash/slag as well as into coarse fly ash (e.g. Ba, Ce, Cs, Mg, Mn, Th),

- group 2 - the elements of medium volatility which pass more into the fly ash than into a bottom ash/slag, they concentrate in fine-grained particles of fly ash (e.g. As, $\mathrm{Cd}, \mathrm{Cu}, \mathrm{Pb}$, $\mathrm{Sb}, \mathrm{Se}, \mathrm{Zn})$;

- group 3 - the elements of high volatility which do not tend to remain in the bottom ash and almost all pass to the flue gases, where they occur partly in the gas phase and partly in the fly ash (e.g. Br, Hg, I).

In the combustion and gasification processes solid byproducts constitute a relatively small percentage of the coal processed. The main products are hot flue gases or syngas. In the case of pyrolysis, an industrial implementation of which is the coking process, the situation is different. The main product of this process is a solid product - coke, the yield of which is ca. $70 \%$. Therefore it should be assumed that behavior of the individual ecotoxic elements in this process may also be different.

The aim of this study was to determine contents of selected ecotoxic elements (mercury, arsenic and lead) in Polish coking coals and in the coking products. In addition, the release coefficients for these elements in the coking process were determined.

\section{Experimental}

\subsection{Samples}

The samples were derived from one of the Polish coking plants using battery with the gravity charging system with an annual production capacity of $560,000 \mathrm{Mg}$ of coke. The coking plant was equiped with the coke gas cooling and purification system, which consisted of: cooling in the collector and precoolers; ammonia absorption in the scrubber; catalytic decomposition of ammonia; production of sulfur from hydrogen sulfide using Claus method as well as absorption of benzo-hydrocarbons by scrub oil. The basic scheme of the coking plant is presented in Fig. 1.

In the study, the samples of coal, coke, coke tar, BTX and sulfur were investigated. In addition, mercury content in purified coke gas was determined.

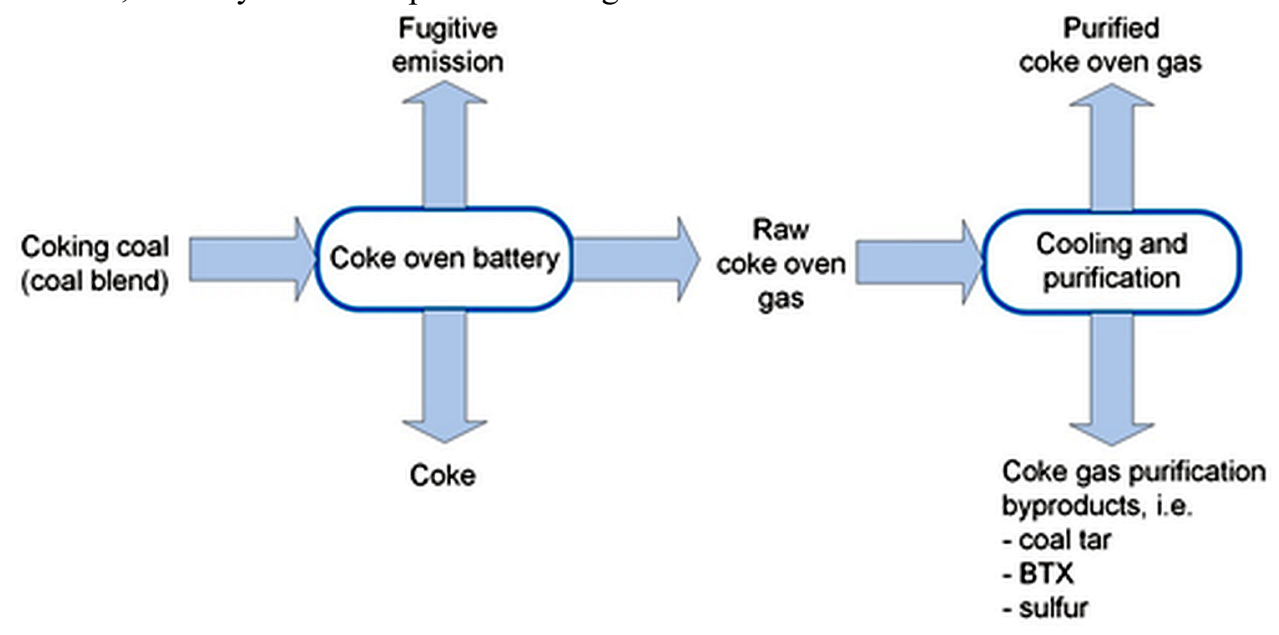

Fig. 1. Basic scheme of the coking plant 


\subsection{Mercury content analysis}

Mercury content in the analyzed samples of coal, coke, coke tar, BTX and sulfur was determined with the use of the MA-2000 Analyzer (Nippon Instruments Corporation) based on cold vapor atomic absorption spectroscopy (CVAAS). The limit of detection was 0.002 $\mathrm{ng}$ and the limit of quantification was $0.006 \mathrm{ng}$. This method is highly linear $(\mathrm{r}=0.9999)$ and the uncertainty at $95 \%$ confidence level ranges from 3 to $10 \%$, depending on the range. The $\mathrm{CV}$-AAS method shows acceptable repeatability and reproducibility across the whole range of the method.

Mercury content in purified coke gas was determined in accordance with an original, selfdeveloped methodology. Purified coke oven gas was isokinetically aspired from the pipe and directed into three parallel lines placed in the thermostatic container. Each line contained mercury traps with a sorbent. The gas flow was approximately $12 \mathrm{dm}^{3} / \mathrm{h}$, with incubation time of around $45 \mathrm{~min}$. The mercury content for each traps was determined using the MA3000 analyzer. Uncertainty at $95 \%$ confidence level for mercury content in gas was $\pm 0.2 \mu \mathrm{g}$ $\mathrm{m}^{-3}$. More details were presented in work [10].

\subsection{Arsenic and lead content analysis}

The content of arsenic in coal, coke and tar samples was determined with the application of Graphite Furnace Atomic Absorption Spectrometer (GFAAS) Hitachi Z-2000 using the Zeeman background correction effect. The applied method was featured by the following analytical parameters: analytical spectral line $193.7 \mathrm{~nm}$; flow of argon: $200 \mathrm{~cm}^{3} \mathrm{~min}-1$ (atomization - $30 \mathrm{~cm}^{3}$ min-1); modifiers: $\mathrm{Ni}$ and $\mathrm{Mg}$ solution. The content of lead was determined using the AAS with flame atomization (FAAS). Before analyses with the use of the AAS, the above-mentioned samples were digested in the Berghoff SpeedWave4 microwave system. Coal and coke samples were mineralized with the combination of spectrally pure nitric acid (V) and hydrofluoric acid. Subsequently, supersaturated boric acid was used as the complexing reagent. Tar samples were mineralized only with pure nitric acid (V). In the case of a low $\mathrm{Pb}$ content, the samples of coal and coke before digestion were ashed at $600{ }^{\circ} \mathrm{C}$.

The content of arsenic and lead in the sulfur samples were determined with the use of the EDXRF Spectrometer, Epsilon 3XLE PANalytical Company. The research showed that the average elemental sulfur content in the samples was $99.276 \pm 0.012 \%$, and the rest was constituted by such elements as: aluminum $(0.176 \pm 0.005 \%)$, silicon $(0.230 \pm 0.004 \%)$, phosphorus $(0.164 \pm 0.03 \%)$, calcium $(0.131 \pm 0.001 \%)$, silver $(200.4 \pm 26.0 \mathrm{mg} \mathrm{kg}-1)$ and tin $(15.1 \pm 4.0 \mathrm{mg} \mathrm{kg}-1)$. The content of $\mathrm{As}$ and $\mathrm{Pb}$ was below the detection limit of the applied method.

\section{Results and Discussion}

The content of ecotoxic elements in the bituminous coals is greatly varied and depends on individual properties of each coal, which are determined primarily by coal bed formation conditions. The significant role of the epigenetic and syngenetic processes should be emphasised [11]. The comparison of mercury, arsenic and lead contents in Polish coking coals and foreign coals is given in table 1 . In the light of the presented data it can be concluded that Polish coking coals are characterized by similar contents of the analyzed ecotoxic elements as in the case of foreign coals. At the same time a significant variation in their content within both coal populations can be observed. In general, mercury content is several dozen times lower than the contents of arsenic and lead, whereas the lead content is 2-3 times higher than the arsenic content. 
Table 1. Comparison of $\mathrm{Hg}$, As and $\mathrm{Pb}$ contents in Polish coking coals and foreign coking coals

\begin{tabular}{|l|c|c|c|}
\hline \multirow{2}{*}{ Coal } & \multicolumn{2}{c|}{ Ecotoxic element content $\mathbf{~} \mathbf{m g} / \mathbf{k g}]$} \\
\cline { 2 - 4 } & $\mathbf{H g}$ & $\mathbf{A s}$ & $\mathbf{P b}$ \\
\hline $\begin{array}{l}\text { Polish coking coals (experimental results of the } \\
\text { presented work) }\end{array}$ & 0.092 & 3.1 & 9.4 \\
\hline Polish coking coals (range) [5,10,12,13] & $0.028-0.183$ & $0.9-8.0$ & $4.9-73.5$ \\
\hline Foreign bituminous coals (arithmetic mean values) [3] & $0.1-0.2$ & $1.5-18.0$ & $10.0-38.0$ \\
\hline $\begin{array}{l}\text { Coals overall [4] } \\
-\quad \begin{array}{l}\text { average for all coals } \\
\text { range of averages } 1 \text { ) }\end{array}\end{array}$ & $\begin{array}{c}0.091 \\
0.03-0.19\end{array}$ & $\begin{array}{c}2.7 \\
0.36-9.8\end{array}$ & $\begin{array}{c}7.0 \\
1.1-22.0\end{array}$ \\
\hline $\begin{array}{l}\text { Total range of ecotoxic element content for all coals } \\
{[3]}\end{array}$ & $0.02-1.0$ & $0.5-80.0$ & $2.0-80.0$ \\
\hline
\end{tabular}

${ }^{1)}$ range of average values for ecotoxic elements in all coals

The conditions in the coke oven chamber, mainly high temperature exceeding $1000{ }^{\circ} \mathrm{C}$, lead to a partial release of ecotoxic elements contained in coal while the rest remains in the final product, i.e. coke. Some of the released ecotoxic elements are emitted to the atmosphere during the operations of charging coke chamber with a coal blend as well as of pushing out the produced coke from the chamber. Along with emission caused by the leaks from the coke oven battery (e.g. through the doors of coke oven chambers), they constitute the so-called fugitive emission [14]. The remaining amount of ecotoxic elements passes to raw coke gas and is further distributed to byproducts of its cooling and purification operations. The values of the fugitive emission factor in the coking process for selected ecotoxic elements are given in Fig 2. With the annual global coke production exceeding $700 \mathrm{mln} \mathrm{Mg}$ [16], the total emission from the coking process reaches: $7 \mathrm{Mg}$ of mercury, $7 \mathrm{Mg}$ of arsenic and $175 \mathrm{Mg}$ of lead.

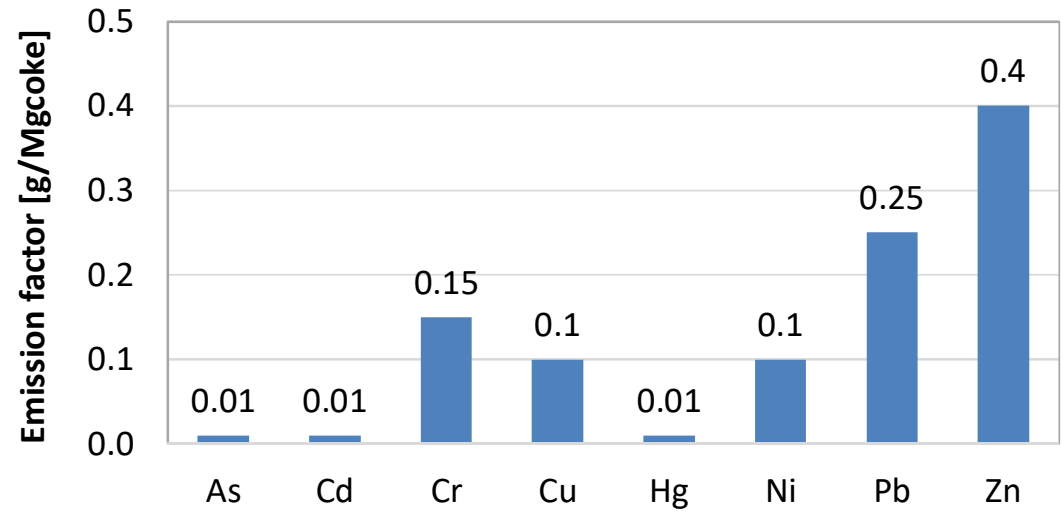

Fig. 2. Fugitive emission factors from the coking process for the selected ecotoxic elements [15]

Due to the specificity of the coking process, including the charging and pushing operations and overpressure prevailing in coke oven chambers, the amount of the fugitive emission depends mainly on the content of ecotoxic elements in coking coal as well as on their volatility. In order to determine the volatility of the analyzed ecotoxic elements the RF factor was proposed - Eq. (1). It is a simple factor describing the amount of the released element in relation to its content in the coal blend subjected to the coking process, presented in percentage unit.

$$
\mathrm{RF}_{\mathrm{i}}=100\left(\mathrm{EE}_{\text {coal-i }}-\gamma_{\text {coke-i }} \mathrm{EE}_{\text {coke-i }}\right) / \mathrm{EE}_{\text {coal-i }}
$$


where:

$\mathrm{RF}_{\mathrm{i}}$ - release factor of the i-th ecotoxic element from coal [\%],

$\mathrm{EE}_{\text {coal-i }}$ - content of the $\mathrm{i}$-th ecotoxic elements in coal $\left[\mathrm{mg} \mathrm{kg}^{-1}\right]$,

$\mathrm{EE}_{\text {coke-i }}$ - content of the $\mathrm{i}$-th ecotoxic elements in coke $\left[\mathrm{mg} \mathrm{kg}^{-1}\right]$,

$\gamma_{\text {coke }}-$ yield of coke [-].

The obtained results are presented in Fig. 3. For comparison, based on literature data, the release factors for the coal combustion and gasification processes were also determined. These factors were determined according to Eq. (1), and the content of ecotoxic element was referred to its content in the solid byproduct derived from these processes i.e. bottom ash or slag. In the light of the presented results, it can be noticed that there are significant differences in the release of the analyzed ecotoxic elements for individual processes. The highest values were obtained for the combustion process and the lowest values for the coking process. That should be explained by a much higher amount of solid product derived from the coking process (coke) as well as by the process conditions. In the coke oven chamber a reductive atmosphere prevails and a diffusion of ecotoxic elements through the coal bed (at a further stage of the coking process through the coke bad) is more difficult. In the coking process, as in a case of the combustion and gasification processes, the highest value of release factor was obtained for mercury, which belongs to the group of elements of the highest volatility. In the coking process lead was characterized by relatively lower values of the release factor. Arsenic was the ecotoxic element for which the lowest values of the release factor were obtained.

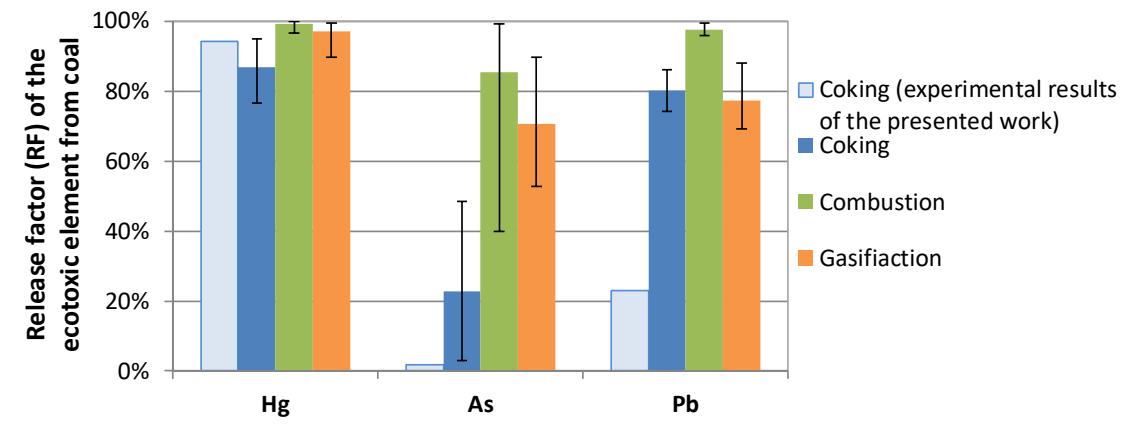

Fig. 3. Average, maximum and minimum values of the release factors of ecotoxic elements from coal in the coking, combustion and gasification processes (based on the authors' results and literature data $[7,10,12,13,17-19])$

The presented differences show that further research regarding the release of ecotoxic elements from coal in the coking process should be carried out. It is necessary to develop a classification of the volatility of ecotoxic elements in the coking process as well.

As mentioned above, a part of the released ecotoxic elements passes to the raw coke gas. During the processes of gas cleaning and cooling, ecotoxic elements are distributed between the purified coke gas and other coking byproducts, i.e. coal tar, BTX, sulfur/sulfuric acid as well as quenching water. In table 2 the contents of mercury, arsenic and lead in coal and products of the coking process are presented. The main product of the coking process, i.e. coke, was characterized by a much lower mercury content and a higher arsenic content than coal. The lead content remained at the same level. Among the coking products, sulfur and coke-oven tar were characterized by the highest content of mercury. Coal tar also had a high content of lead. The contents of arsenic and lead in sulfur were below the detection limit. 
Table 2. Ecotoxic elements content in analyzed samples of coal and products of the coking process (average values)

\begin{tabular}{|c|c|c|c|}
\hline \multirow{2}{*}{$\begin{array}{c}\text { Coal/ } \\
\text { coking product }\end{array}$} & \multicolumn{4}{|c|}{ Ecotoxic element content $\mathbf{m g} / \mathbf{k g}]$} \\
\cline { 2 - 4 } & $\mathbf{H g}$ & $\mathbf{A s}$ & $\mathbf{P b}$ \\
\hline Dry coal & 0.091 & 3.1 & 9.4 \\
\hline Dry coke & 0.007 & 4.0 & 9.5 \\
\hline Coal tar & 2.008 & 1.8 & 99.1 \\
\hline Sulfur & 2.998 & $<\mathrm{dl}^{\mathrm{b}}$ & $<\mathrm{dl}^{\mathrm{b}}$ \\
\hline BTX & 0.019 & $\mathrm{~nm}^{\mathrm{c}}$ & $\mathrm{nm}^{\mathrm{c}}$ \\
\hline Coke oven gas & $\begin{array}{c}0.015 \\
7.5^{\mathrm{a}}\end{array}$ & $\mathrm{nm}^{\mathrm{c}}$ & $\mathrm{nm}^{\mathrm{c}}$ \\
\hline
\end{tabular}

Based on the result of mass balance studies in the coking plant [10], the mercury balance in the coking process was established (Fig. 4). Only $6 \%$ of the mercury contained in coal remains in coke while the remaining amount passes to coking products $(80 \%)$ and is emitted into the atmosphere in the form of fugitive emission (14\%). The coal tar is a coking product in which the largest amount of mercury is accumulated (75\%).

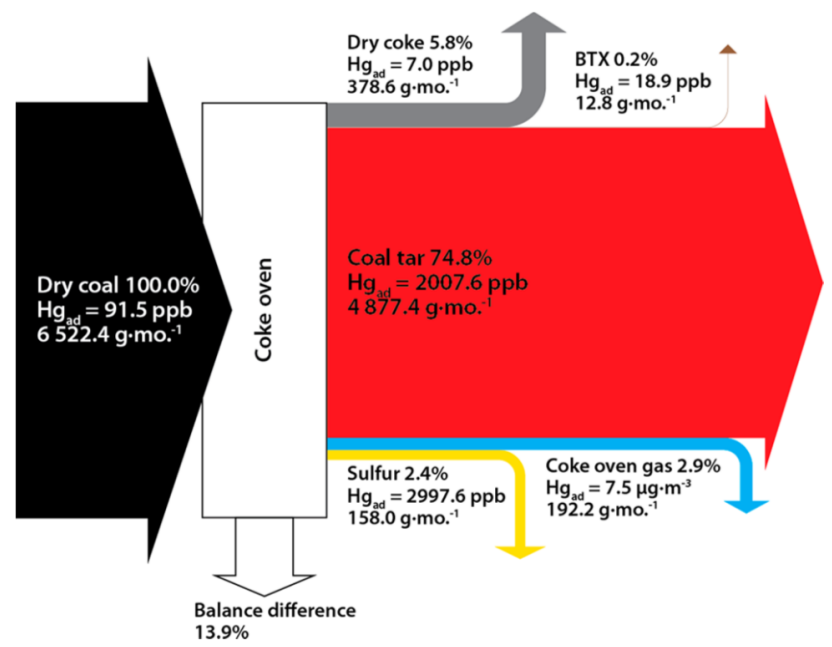

Fig. 4. Mercury balance in the coking process (mo. - month) [10]

It should be noted that the release of the ecotoxic elements from coal in the coking process is also advantageous due to the possibility of reducing their content in coke (table 3). In table 3 the values of the enrichment factor of the analyzed ecotoxic elements in coke are also presented. The values were calculated as a ratio of the ecotoxic element content in coke to its content in coal, presented in percentage units - Eq. (2). Values higher than $100 \%$ mean an increase in the ecotoxic element content in coke, and values less than $100 \%$ mean its decrease.

In coke a significant reductions in mercury content (to $16 \%$ of $\mathrm{Hg}$ content in coal) as well as in lead content (to $41 \%$ of $\mathrm{Pb}$ content in coal) are observed. It should be noted that for the analyzed coke the lead content did not decrease. However, it was at a relatively low level of $9.5 \mathrm{mg} \mathrm{kg}^{-1}$. In the case of arsenic a decrease in its content in coke was not noticed, which should be explained by its low volatility - Fig. 2 .

$$
E F_{i}=100\left(E E_{\text {coke-i }} E E_{\text {coal-i }}^{-1}\right)
$$


where:

$\mathrm{EF}_{\mathrm{i}}-$ enrichment factor of $\mathrm{i}$-th ecotoxic element in coke [\%],

$\mathrm{EE}_{\text {coke-i }}$ - content of the i-th ecotoxic elements in coke $\left[\mathrm{mg} \mathrm{kg}^{-1}\right]$,

$\mathrm{EE}_{\text {coal-i }}$ - content of the i-th ecotoxic elements in coal $\left[\mathrm{mg} \mathrm{kg}^{-1}\right]$.

Table 3. Comparison of the contents of ecotoxic elements in Polish coking coals and in cokes produced from these coals

\begin{tabular}{|l|c|c|c|}
\hline \multirow{2}{*}{ Coal/coke/enrichment factor } & \multicolumn{3}{|c|}{ Ecotoxic element content } \\
\cline { 2 - 4 } & $\mathbf{H g}$ & $\mathbf{A s}$ & $\mathbf{P b}$ \\
\hline Polish coking coals, [mg/kg] & & & \\
- average [12,13] & 0.077 & 4.5 & 59.9 \\
- $\quad$ range [12,13] & $0.061-0.097$ & $2.4-8.0$ & $46.2-73.5$ \\
- experimental results of the presented work & 0.092 & 3.1 & 9.4 \\
\hline Cokes made from Polish coking coals, [mg/kg] & & & \\
- average [12,13] & 0.013 & 4.5 & 17.6 \\
- range [12,13] & $0.007-0.021$ & $2.1-7.5$ & $9.1-26.1$ \\
- experimental results of the presented work & 0.007 & 4.0 & 9.5 \\
\hline Enrichment factor, [\%] & & & \\
- overall [12,13] & 16 & 105 & 41 \\
- experimental results of the presented work & 8 & 129 & 101 \\
\hline
\end{tabular}

\section{Conclusions}

On the basis of the obtained results the following conclusions have been formulated:

i. In the coking process mercury is characterized by the highest values of the release factor. Lower values of the release factor are recorded for lead and very low values for arsenic.

ii. There are significant differences in the release of the analyzed ecotoxic elements in the coking process in comparison with the combustion and gasification processes. That can be explained by a much higher amount of the solid product derived from the coking process (i.e. coke) as well as by the specific process conditions. Therefore, further research regarding the release of ecotoxic elements from coal in the coking process should be carried out and it is necessary to develop a classification of the ecotoxic elements according to their volatility in the coking process.

iii. Coke is characterized by a much lower content of mercury and lead than coal, and by a similar content of arsenic. Among the coking products, sulfur and tar are characterized by the highest content of mercury. Coal tar also contains a high amount of lead.

iv. Only $6 \%$ of the mercury contained in coal remains in coke while the remaining amount passes to coking products $(80 \%)$ and is emitted into the atmosphere in the form of fugitive emission (14\%). The coal tar is a coking product in which the largest amount of mercury is accumulated (75\%).

This paper was prepared as a part of the statutory activity of the Faculty of Energy and Fuels at the AGH University of Science and Technology, No. 11.11.210.373 


\section{References}

1. J.H. Duffus, Pure App. Chem.,74 (5), 793 (2002).

2. WHO, Trace elements in human nutrition and health, Geneva (1996).

3. M. Xu, R. Yan, C. Zheng, Y. Qiao, J. Han, C. Sheng, Fuel Process. Technol. 85, 215 (2003).

4. H. Nalbandian, Trace element emissions from coal, IEA Clean Coal Centre (2012).

5. D. Makowska, F. Wierońska, T. Dziok, A. Strugała, Polityka Energetyczna - Energy Policy Journal 20(4), 89 (2017).

6. KOBiZE, Krajowy bilans emisji $\mathrm{SO}_{2}, \mathrm{NO}_{X}, \mathrm{CO}, \mathrm{NH}_{3}, \mathrm{NMLZO}$, pyłów, metali ciężkich $i$ TZO za lata 2015-2016 w ukladzie klasyfikacji SNAP - Raport syntetyczny, Warszawa (2018).

7. P. Burmistrz, K. Kogut, M. Marczak, J. Zwoździak, Fuel Process. Technol. 152(11), 250 (2016).

8. P. Porada, T. Dziok, G. Czerski, P. Grzywacz, A. Strugała. Gospodarka Surowcami Mineralnymi - Mineral Resources Management 33(1), 15-34 (2017).

9. L.B. Clarke, L.L. Sloss, Trace elements - emissions from coal combustion and gasification, IEA Coal Research, Londyn (1992).

10. P. Burmistrz, K. Kogut, M. Marczak, T. Dziok, J. Górecki, Energy Fuels 32(5), 5677 (2018).

11. T. Dziok, A. Strugała, A. Włodek, Environ. Sci. Pollut. Res. (2018) https://doi.org/10.1007/s11356-018-1667-1

12. J. Konieczyński, E. Zajusz-Zubek, M. Jabłońska, The Scientific World Journal, 2012 Article ID 294927 (2012).

13. E. Zajusz-Zubek, J. Konieczyński, Fuel 82, 1281 (2003).

14. US EPA - United States Environmental Protection Agency Locating and estimating air emissions from sources of mercury and mercury compounds, EPA-454/R-97-012 (1997).

15. EMEP/CORINAIR, Emission Inventory Guidebook, Solid fuel transformation plants, Activities 010406 \& 040201 (2006).

16. K. Mysiak, M. Jarno. Current situation on the world market of coking coal and coke. (Cokemaking Conference, Ustorń, Poland 2016).

17. M. Tolvanen, Mass balance determination for trace elements at coal -, peat- and barkfired power plants, VTT PUBLICATIONS 524 (2004).

18. F. Wierońska, D. Makowska, A. Strugała, E3S Web of Conferences 14, 02006 (2017).

19. Y. Wang, Y. Tang, S. Liu, Y. Wang, R.B. Finkelman, Fuel Process. Technol. 177, 140 (2018). 